\title{
Candida Albicans Bone Rib Osteomyelitis due to Previous Systemic Candidiasis
}

\author{
Delfanti $\mathbf{R}^{1}$, Conti $\mathrm{L}^{1 *}$, Fronti $\mathrm{E}^{2}$, Ratti $\mathrm{G}^{2}$, Zangrandi $\mathrm{A}^{3}$ and Capelli $\mathrm{P}^{1}$ \\ ${ }^{1}$ Department of Surgery, Ausl Piacenza, Italy \\ ${ }^{2}$ Department of Infectious Disease, Ausl Piacenza, Italy \\ ${ }^{3}$ Department of Histopathology, Ausl Piacenza, Italy
}

Submission: July 09, 2018; Published: July 20, 2018

*Corresponding author: Luigi Conti, Department of Surgery, AUSL Piacenza,Via Taverna 49, 29121 Piacenza, Italy, Tel: (39) 0523 303162, (39) 3334043148; Email: dr.luigiconti@gmail.com

Abstract

Candida albicans osteomyelitis causes significant morbidity if not recognized early. Due to its rarity and chronic course symptoms may persist for months before diagnosis is suspected. Pathogenesis is related to previous candidemia and costochondral joints represent an usual localization.

Keywords: Candida albicans; Osteomyelitis; Costochondral junction; Candidemia

Abbreviations: CA: Candida Albicans; ICU: Intensive Care Unit; WBC: White Blood Cells; CT: Computed Tomography

\section{Introduction}

A 45-years old man referred to our unit for a painful and swelling mass in the right inferior parasternal joint. The mass appeared several months before, without sings of resolution despite empiric antibiotical therapy. Remarkable in patient's medical history was that on July 2017 a routine coronary angiography caused total dissection of his right coronary artery up to the main coronary sinus, treated by emergency surgical repair and coronary by-pass. After surgery the patient developed a bilateral pneumonia with excavated abscess in the lung after a long invasive ventilation; multi drugs resistant Acinetobacter was isolated in bronchial lavage with Klebsiella Pneumoniae plus Candida Albicans isolated in blood cultures. The CT study showed an area of bone erosion in the seventh right rib at the costo-chondral junction with related abscess in the chest wall up to the skin. The patient was treated surgically by en-block resection of the involved bone and chest wall abscess, with reconstruction of the chest wall made by polyglactin knitted (Vycril ${ }^{\circledR}$ ) associated with a prolonged anti-mycotic therapy.

\section{Conclusion}

Post-surgical C.A. osteomyelitis is more often due to direct insemination and it is subsequent to C.A. hematogenous spread in people harboring predisposing factors like recent major surgery, immunosupression and prolonged ICU stay.

\section{Case Description}

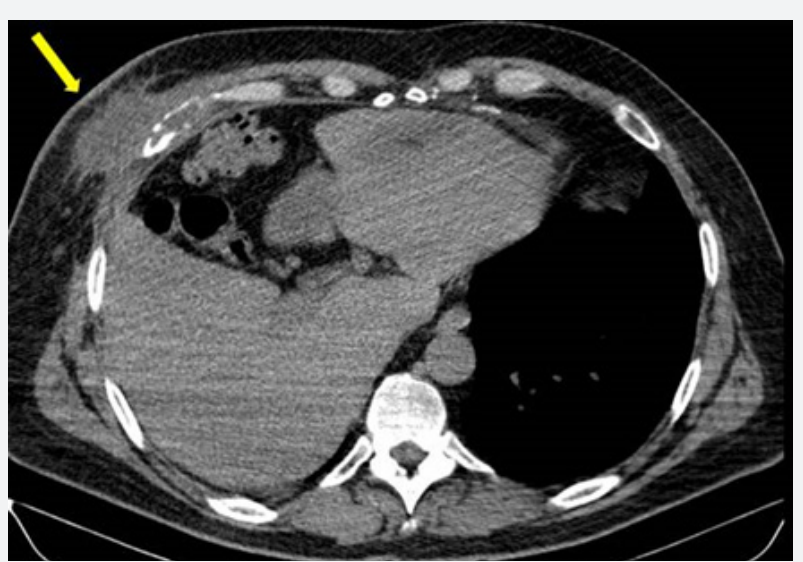

Figure 1: Thoracic CT scan, transverse section showing bone erosion of the seventh right rib at the costo-chondral junction with related abscess in the chest wall

On January 2018 a 45 years old man referred to our unit for a painful and swelling mass in the right inferior parasternal joint. The mass appeared several months before, without sings of resolution despite empiric antibiotical therapy. Remarkable in patient's medical history was that on July 2017 a routine coronary angiography caused total dissection of his right coronary artery up to the main coronary sinus, treated by emergency surgical repair and coronary by-pass. After surgery 
the patient had a prolonged ICU stay with prolonged mechanical ventilation developinga bilateral pneumonia with excavated abscess in the lung. Multi drugs resistant Acinetobacterwas isolated in bronchial lavage and Klebsiella Pneumoniae plus Candida Albicans were isolated in blood cultures.

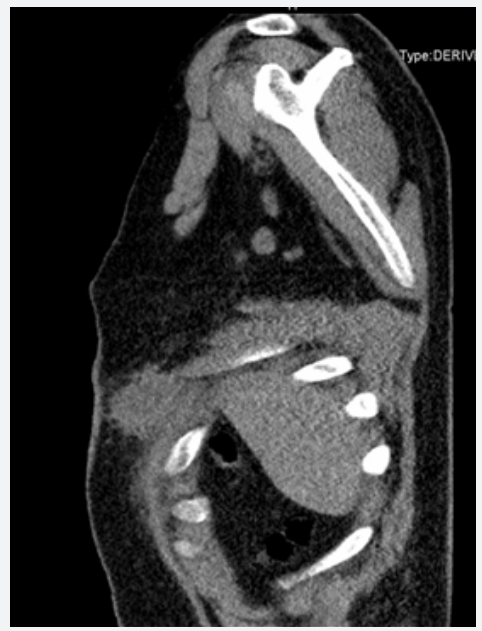

Figure 2: Thoracic CT scan, sagittal section.

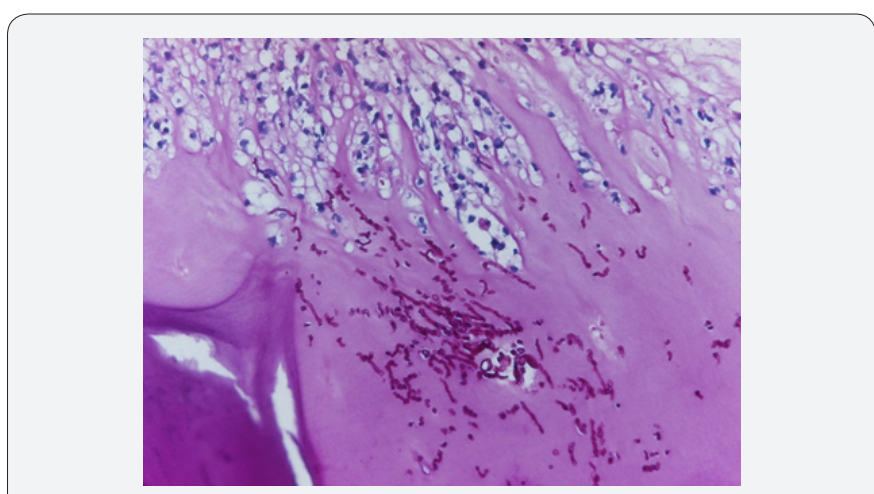

Figure 3: Histopathological sample of the abscess with presence of mycotic hyphae

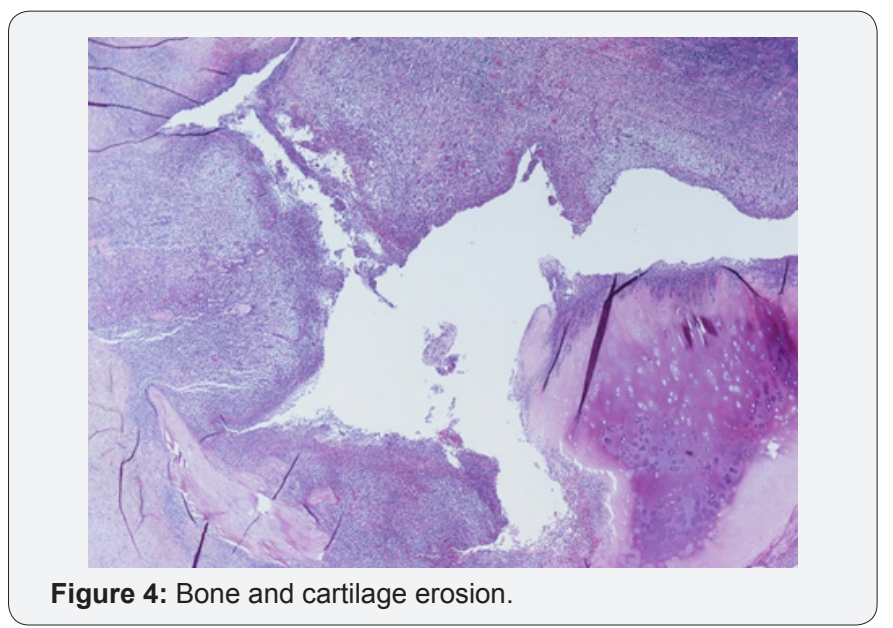

A various range of antibiotical and antimycothic therapy was performed, and finally the patient was discharged from ICU in September and he finally was discharged in November 2017. After ICU discharge he presented the same swelling and painful mass in lower right parasternal region as we observed; previous median sternotomy presented well consolidated, far and without any involvement in the abscess. On admission he had no fever and normal WBC count; the CT study showed an area of bone erosion in the seventh right rib at the costo-chondral junction with related abscess in the chest wall up to the skin (Figure 1 \& 2) and confirmed no involvement of the sternotomy. He was treated surgically by en-block resection of the involved bone and chest wall abscess, with reconstruction of the chest wall made by polyglactin knitted (Vycril@, Ethicon) absorbable mesh fixed on the near ribs.Histopathology samples confirm abscess and bone erosion with presence of mycotic hyphae inside (Figure 3 \& 4); culture samples from bone were positive for C.A.Promptly specific medical therapy against C.A. was started and planned for a six months lasting period. In the eleventh post-operative day he was discharged at home with oral therapy with fluconazole $600 \mathrm{mg}$ per day for six months.

\section{Discussion}

The first reports about costo-chondral involvement in systemic candidiasis dates the eighties and intravenous heroin addicts were involved [1]. Typically, the lack of hygiene in their intravenous injection causes C.A. hematogenous dissemination and subsequent osteoarticular involvement mainly in costo-chondral joint [2]. C.A. hematogenous spread and immunosuppression plays an important role in the pathogenesis for non-traumatic patients or without direct local insemination.C.A. osteomyelitis may be divided in proven osteomyelitis (i.e. compatible clinical characteristics, radiological appearance and positive cultures) or only probable (i.e. positive cultures from bone).Due to its rarity and chronic course symptoms persists for weeks or months before diagnosis is suspected. A swelling mass with pain and edema represents the usual presentation; high fever and important increase of inflammatory markers is unusual.Diagnosis confirmation is made on CT appearance and, as treatment by surgical debridement or resection is mandatory, on cultures and histopathology of surgical specimens.In 2009 IDSA guidelines recommended antifungal therapy lasting at least six months [6] and state that premature discontinuation in medical therapy represents the leading cause of disease relapse [1,6].

\section{Conclusion}

Postsurgical C.A. osteomyelitis is uncommon and more often due to direct insemination1; more rarely, like in our report, it can be subsequent to C.A. hematogenous spread. This kind of pathogenesis with elective localization in the costo-chondral junction was first reported in the eighties in intravenous heroin addict [2]. In more recent times it is anedottically reported in people harboring predisposing factors like recent major surgery, immunosuppression and prolonged ICU stay [1,3-5].

\section{Lesson learned}

Due to its rarity C.A. osteomyelitis is not suspected and the diagnosis is done after weeks or months of pain and inadequate 
antimicrobial therapy, causing significant morbidity.Prolonged medical therapy is not enough to solve the problem and surgical debridement is needed. This can also confirm the diagnosis and drive the therapy by culture samples.Despite aggressive surgery, prolonged anti-mycotic therapy for at least six months is needed and early discontinuation of the therapy represents the leading cause of infection relapse $[1,6,7]$. Reconstructing material interposition represents a predisposing factor for persistent infection, so the prompt use of metal materials for bone reconstruction should be avoided. State the need of prolonged medical therapy we decided for a temporary reconstruction of the chest wall made by absorbable material, that won't be in site at the end of the six months therapy. If bone reconstruction made by metal material is needed for aesthetic or functional problems it can be deemed at the time of local sterilization.

\section{Acknowledgment}

Drs. Ratti and Fronti kindly provided important indications for treatment protocols and diagnosis of the CA infection

Dr. Zangrandi kindly provided the histopathological sample images for publication

\section{Conflicts of interest}

The authors have no conflicts of interest to disclose

\section{References}

1. MN Gamaletsou, DP Kontoyiannis, NV Sipras, B Moriyama, E Alexander, et al. (2012) Candida osteomyelitis: Analysis of 207 pediatric and adult cases. Clin Infect Dis 55(10): 1338-1351.

2. JM Miro, MA Brancos, R Abello, F Lomena, J Bisbe, et al. (1988) Costochondral involvement in systemic candidiasis in heroin addicts: clinical, scintigraphic and histologic features in 26 patients. Arthritis and Rheumatism 31(6): 793-797.

3. S Eves, R Sayeed, M Potter (2014) A case of rib fungal osteomyelitis. J Plast Reconstr Aesthetic Surg 67(3): 81-83.

4. R Magano, J Cortez, E Ramos (2015) Candida albicans osteomyelitis as a cause of chest pain and visual loss. BMJ Case Rep 16: 324-327.

5. F Arias, S Mata Essayag, ME Landaeta, C Hartung de Capriles, C Perez, et al. (2004) Candida albicans osteomyelitis: case report and literature review. Intern J Infect Diseases 8(5): 307-314.

6. PG Pappas, CA Kauffman, D Andes, DK Benjamin, TF Calandra, et al. (2009) Infectious Diseases Society of America. Clinical practice guidelines for the management of candidiasis: 2009 update by the Infectious Diseases Society of America. Clin Infect Dis 48(5): 503-535.

7. AK Slenker, SW Keith, DL Horn (2012) Two hundred and eleven cases of candida osteomyelitis: 17 case reports and a review of the literature Diagn Microbiol Infect Dis 73(1): 89-93.

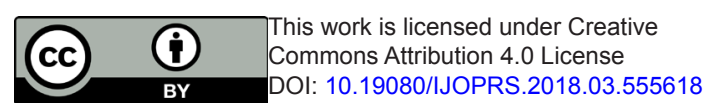

\begin{tabular}{l} 
Your next submission with Juniper Publishers \\
will reach you the below assets \\
- Quality Editorial service \\
- Swift Peer Review \\
- Reprints availability \\
- E-prints Service \\
- Manuscript Podcast for convenient understanding \\
- Global attainment for your research \\
- Manuscript accessibility in different formats \\
( Pdf, E-pub, Full Text, Audio) \\
- Unceasing customer service \\
Track the below URL for one-step submission \\
https://juniperpublishers.com/online-submission.php \\
\hline
\end{tabular}

